\title{
Clinical Characteristics and Survival Associations of Pancreatic Neuroendocrine Tumor: Does Age Matter?
}

\section{Mengqi Liu}

Fudan University Shanghai Cancer Center

Xiaoyan Sun

Zhengzhou University First Affiliated Hospital

Zheng Zhang

Fudan University Shanghai Cancer Center

Xiaowu Xu

Fudan University Shanghai Cancer Center

Xianjun Yu

Fudan University Shanghai Cancer Center

\section{Qifeng Zhuo}

Fudan University Shanghai Cancer Center

Shunrong Ji ( $\sim$ jishunrong@fudanpci.org )

Fudan University Shanghai Cancer Center https://orcid.org/0000-0003-2556-3320

\section{Research}

Keywords: clinical characteristics, pancreatic, neuroendocrine tumor, age, survival

Posted Date: May 29th, 2020

DOI: https://doi.org/10.21203/rs.3.rs-31255/v1

License: (c) (i) This work is licensed under a Creative Commons Attribution 4.0 International License. Read Full License 


\section{Abstract}

Background: Pancreatic neuroendocrine tumor (pNET) is the second most common epithelial neoplasm of pancreas. As in pancreatic adenocarcinoma, patients with different onset ages display different clinical features and prognosis, we divided pNET patients into early-onset pancreatic neuroendocrine tumor (EOpNET) and typical age-at-onset pancreatic neuroendocrine tumor (TOpNET) to investigate the effect of onset age on its clinical characteristics and prognosis.

Methods: Data were collected from the Surveillance, Epidemiology, and End Results (SEER) database (2004-2015; cohort 1) and Fudan University Shanghai Cancer Center (FUSCC) (2005-2018; cohort 2) retrospectively. The clinical characteristics were compared using chi-squared tests. Cox proportional hazards regression was used to evaluate hazard ratios (HRs) and 95\% confidence intervals (Cls), and overall survival were formulated by Kaplan-Meier curves.

Results: In total 5,368 and 330 patients' data were included from the SEER database and FUSCC. Gender had no effect on survival in EOpNET group. Tumors locating in the tail (HR: $0.721,95 \% \mathrm{Cl}: 0.63-0.83, \mathrm{P}<0.001)$ and body (HR: $0.712,95 \% \mathrm{Cl}: 0.60-0.85, \mathrm{P}=0.001)$ had lower risks of death compared to tumors in the head in TOpNET group. The overall survival of EOpNET (136 (3-143) months) was better than TOpNET (85 (3-143) months) ( P < 0.001) in SEER database. The results in FUSCC was similar with SEER cohort.

Conclusions: EOpNET group had significantly better overall survival than TOpNET though their clinical characteristics were not significantly different. In the future personalized treatment of pNET, the onset age of patients will become another important factor for guiding the treatment and prognosis.

\section{Background}

Pancreatic neuroendocrine tumor (pNET) is the second most common pancreatic neoplasms with relatively inert biological behavior compared to pancreatic adenocarcinoma.[1] However the incidence of it has increased steadily in recent decades[2], probably due to more sensitive detection methods and more frequent routine examinations among people. $[3,4]$ Recent reports suggest that early-onset pancreatic cancer (EOPC) which was defined as pancreatic adenocarcinoma (PDAC) with onset age before 50 display distinct clinical characteristics and overall survivals compared with other patients of this disease, and constitute $5-10 \%$ of all PDAC cases[5-7]. According to the reports, the mean age at diagnosis of pNET is 56.8 years old, and also a small proportion of cases are diagnosed in younger age[8]. However, research on the differences between early-onset pancreatic neuroendocrine tumor (EOpNET) and typical ageat-onset pancreatic neuroendocrine tumor (TOPNET) are very limited, probably due to difficulties in studying rare disease subset with lower incidence. Most studies are descriptive and only include relatively small populations lacking a typical age at diagnosis comparison group. In the recent repot of Wang et al., onset age has an important impact on the overall survival and a factor which should be considered in the future pNETs staging systems[9]. To identify whether onset age of pNET has similar effects in patients as in PDAC, we conducted this study to evaluate the associations between clinical characteristics and prognosis by age at diagnosis of pNET, and how early-onset pNET (EOpNET) differs from typical age-onset pNET (TOpNET).

\section{Methods}

\section{Patients and Data Collection}

Pathologically confirmed pNET cases from 2004 to 2015 were retrieved from the SEER database. Patients with pancreatic cancer were collected according to the 2nd and 3rd editions of the International Taxonomy (ICD-0-2 / 3): C25.0 to C25.9.9. The diagnostic codes used for searching are as follows: 8150 (Pancreatic endocrine tumor) $₫ 8151$ (Insulinoma) $₫ 8152$ (Glucagonoma) $₫ 8153$ (Gastrinoma) $₫ 8155$ (Vipoma) $₫ 8156$ (Somatostatinoma) $₫ 8240$ (Carcinoid tumor), 8241 (Enterochromaffin cell carcinoid) $₫ 8242$ (Enterochromaffin-like cell tumor) $₫ 8243$ (Goblet cell carcinoid) $₫ 8246$ (Neuroendocrine carcinoma) 8249 (Atypical carcinoid tumor). And TNM data were collected according to the codes below: derived the American Joint Committee on Cancer (AJCC) stage group 6th ed (2004+)『collaborative stage (cs) tumor size 2004, lymph nodes 2004, metastasis at dx 2004, regional nodes positive (1988+), and regional nodes examined (1988+). Basic clinicopathologic characteristics were retrieved including gender, age, race, surgery, location of the primary site, and differentiation.

And then a single center series of Fudan University Shanghai Cancer Center (FUSCC) was analyzed and patients who were pathologically diagnosed of pNET were included. The demographic data including gender, age, grade, location of the primary site and surgical status were collected. And the data of tumor $T$ stage, nodal status and metastases were also retrieved and classified according to the $8^{\text {th }}$ AJCC staging classification. The follow-up data were confirmed by review of medical records monthly and contacting the patients or their relatives to ascertain disease progression or date of death if applicable.

Our hospital Ethics Committee approved the study and written informed consent were acquired from all participants in the study. We excluded patients with overall survival time less than 3 months to rule out perioperative mortality in both cohorts.

\section{Statistical Analysis}

For statistical analysis we defined patients with age $<50$ years as early-onset pNET (EOPNET) and age $\geq 50$ years as typical age-at-onset pNET (TOpNET) at the time of diagnosis. Means for baseline clinical features were compared by chi-squared tests or sample t-tests. The survival time starts from the date of first diagnosis and ends at the time of the last follow-up or death. Log-rank tests were used to analyze the overall survival and Kaplan-Meier method were used to compare the survival proportions. Univariate survival analysis of age, sex, grade, surgery, tumor location and so on were performed by Cox proportional hazards regression. Hazard ratios (HRs) and corresponding 95\% confidence intervals ( $95 \% \mathrm{Cls}$ ) were calculated. SPSS Statistics version 21.0 software (IBM Corp, Armonk, NY, USA) and GraphPad Prism 7.0 were used for the statistical analyses. All tests were two-sided and tests with $P$ values less than 0.05 were considered statistically significant. 


\section{Results}

In total, 5,368 patients were pathologically diagnosed of pNET in the SEER database and included in the study (Table 1), including 1203 (22.4\%) EOpNET patients and 4165 (77.6\%) TOPNET patients, respectively. While the male/female ratio was around 1:1 in EOpNET patients (1:1.05) which was similar to previous reports[7, 8], the proportion of male in TOpNET patients was significantly higher than female $(1.30: 1, P<0.001)$. Approximately half of the patients had a tumor located in the body and/or tail of the pancreas in both groups (45.2\% and $48.1 \%$ ). $92.5 \%$ and $89.4 \%$ patients had low or intermediate differentiated tumors in EOpNET group and TOPNET group respectively. Furthermore, significantly higher proportion of patients in EOpNET group received

surgery treatment $(P<0.001)$ than TOpNET group. The median survival period for EOpNET group was 136 (3-143) months and for TOpNET group was 85 (3143) months $(P<0.001)$. Factors associated with survival were evaluated by Univariate Cox proportional hazards models in both groups. We found that even though gender had no effect on the survival of EOpNET group, it seems that females had a lower risk of death than males in TOpNET group (HR: $0.871,95 \% \mathrm{Cl}$ : $0.79-0.97, P=0.010)$. Moreover, the married people had lower risks of death than the singles in both EOpNET group (HR: $0.729,95 \% \mathrm{Cl}: 0.57-0.94, P=0.014)$ and TOpNET group (HR: $0.843,95 \% \mathrm{Cl}: 0.71-1.00, P=0.047$ ). Compared to the patients diagnosed at 2004 to 2009 , the patients diagnosed at 2010 to 2015 had significantly better prognosis in both EOpNET group (HR: $0.750,95 \% \mathrm{Cl}: 0.59-0.96, P=0.020)$ and TOpNET group (HR: $0.799,95 \% \mathrm{Cl}$ : $0.71-0.89, P<$ 0.001). In relations to the T stage of pNET, we found that T2 stage patients had 3.167-fold increased death risk compared to T1 stage patients in TOpNET group (HR: 3.167, 95\%Cl: $2.40-4.19, P<0.0001$ ), while there was no difference in TOpNET group (HR: $1.294,95 \% \mathrm{Cl}: 0.80-2.11, P=0.300$ ), and similar results were observed in patients with pathological grade II differentiation. Compared to tumors located in pancreatic head, tumors in the body (HR: $0.712,95 \% \mathrm{Cl}$ : $0.60-0.85, P=0.001$ ) and tail (HR: $0.721,95 \% \mathrm{Cl}: 0.63-0.83, P<0.001$ ) had lower risk of death in TOpNET group, while the location had no efficacy on survival in EOpNET group. Surgery reduced the risks of death in both EOpNET group (HR: $0.128,95 \% \mathrm{Cl}: 0.10-0.16, P<0.001)$ and TOpNET group (HR: 0.191 , $95 \% \mathrm{Cl}: 0.17-0.22, P<0.001)$ respectively. 


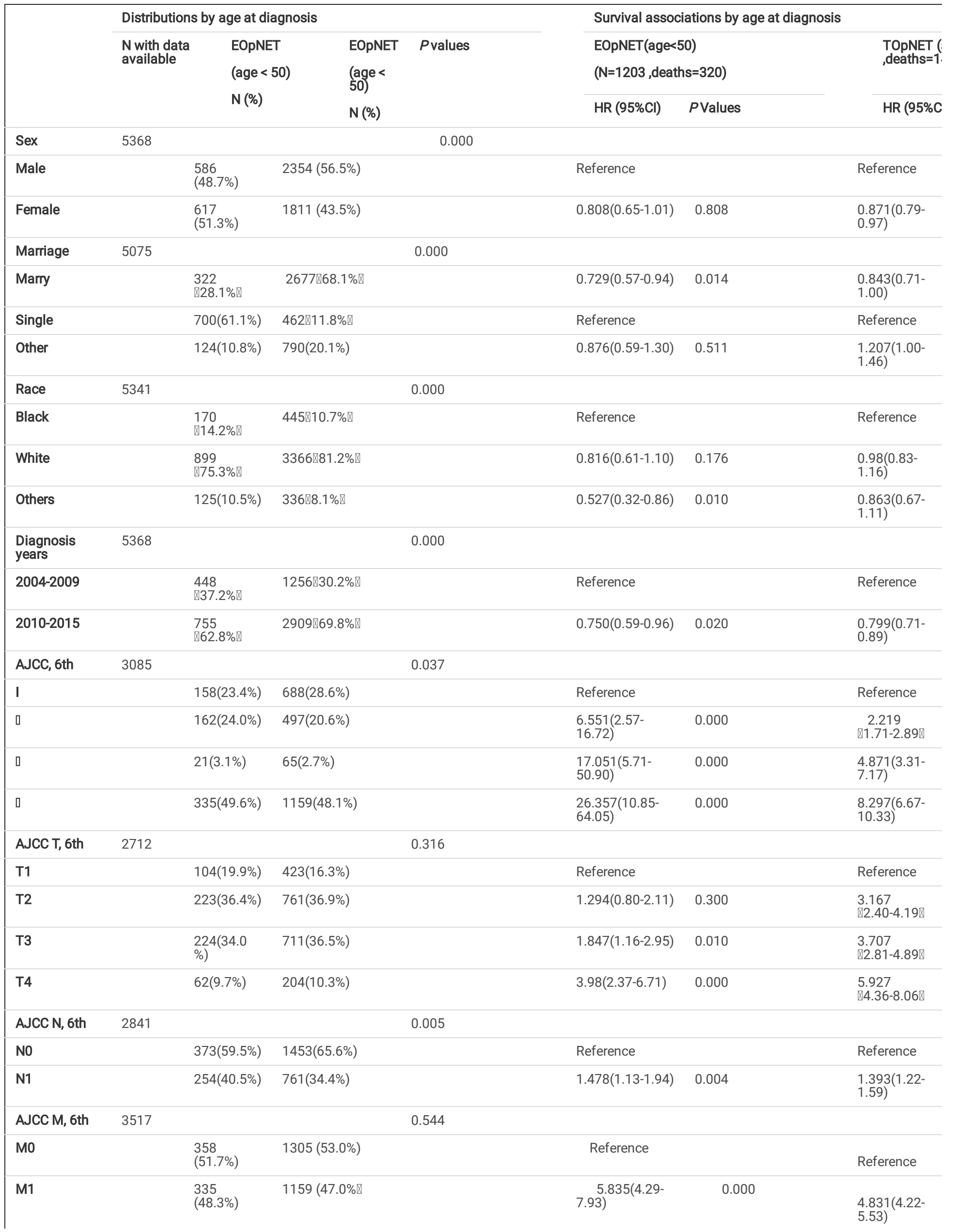

Page 4/9 


\begin{tabular}{|c|c|c|c|c|c|c|c|}
\hline Differentiation & 3492 & & & 0.067 & & & \\
\hline I & & $\begin{array}{l}577 \\
(72.2 \%)\end{array}$ & 1897 (70.4\%) & & Reference & & Reference \\
\hline II & & $\begin{array}{l}162 \\
(20.3 \%)\end{array}$ & $511(19.0 \%)$ & & $1.299(0.81-2.10)$ & 0.284 & $1.638(1.3$ \\
\hline III & & $48(6.0 \%)$ & $215(8.0 \%)$ & & $6.661(4.27-10.40)$ & 0.000 & $5.771(4.7$ \\
\hline IV & & $12(1.5 \%)$ & $70(2.6 \%)$ & & $6.949(3.00-16.09)$ & 0.000 & $6.553(4.8$ \\
\hline Primary site & 5368 & & & 0.335 & & & \\
\hline Head & & $\begin{array}{l}349 \\
(29.0 \%)\end{array}$ & $1151(27.6 \%)$ & & Reference & & Reference \\
\hline Body & & $\begin{array}{l}155 \\
(12.9 \%)\end{array}$ & $581(13.9 \%)$ & & $0.802(0.53-1.22)$ & 0.304 & $0.712(0.6$ \\
\hline Tail & & $\begin{array}{l}388 \\
(32.3 \%)\end{array}$ & $1423(34.2 \%)$ & & $0.877(0.66-1.17)$ & 0.378 & $0.721(0.6$ \\
\hline Others & & $\begin{array}{l}311 \\
(25.9 \%)\end{array}$ & $1010(24.2 \%)$ & & $1.363(1.04-1.79)$ & 0.027 & $1.057(0.9$ \\
\hline $\begin{array}{l}\text { Surgery } \\
\text { treatment }\end{array}$ & 5303 & & & 0.000 & & & \\
\hline No & & $\begin{array}{l}393 \\
(33.1 \%)\end{array}$ & 1665 (40.5\%) & & Reference & & Reference \\
\hline Yes & & $\begin{array}{l}796 \\
(66.9 \%)\end{array}$ & 2449 (59.5\%) & & $0.128(0.10-0.16)$ & 0.000 & $0.191(0.1$ \\
\hline $\begin{array}{l}\text { Median } \\
\text { survival } \\
\text { time(range), } \\
\text { months }\end{array}$ & & $136(3-143)$ & $85(3-143)$ & 0.000 & & & \\
\hline
\end{tabular}

Table 1

Characteristic distributions and survival associations by age at diagnosis among pancreatic neuroendocrine tumor (pNET) cases in SEER database Totally 330 patients from Fudan University Shanghai Cancer Center (FUSCC) were pathologically diagnosed of pNETs and included in this study (Table 2), including $126(38.2 \%)$ EOpNET patients and 204 (61.8\%) TOpNET patients, respectively. The proportion of female in EOpNET group was higher than in TOPNET group, but was not statistically significant $(P=0.362)$. The ratio of tumor location (Head:body and/or tail) in pancreas of both groups were 1:1.7. Majority of patients were G1 or G2 tumors in both EOPNET group (87.0\%) and TOpNET group (86.5\%). Compared with SEER database, higher proportion of patients in our institution received surgery treatment in both EOPNET and TOpNET groups but was not statistically significant $(P=0.977)$. The median followup time in EOpNET group was 47.97 (3.6-152.83) months and in TOpNET group was 43.87 (4.33-128.67) months. G2 and G3 tumors had a 9-fold and 30fold increased risk of death compared to $\mathrm{G} 1$ tumours in EOpNET group (HR: 9.437, 95\% Cl: $1.22-73.16, P=0.032 ; \mathrm{HR}: 30.44,95 \% \mathrm{Cl}: 3.81-243.50, P=0.001$ ), however the risks in TOpNET group were only 1.468-fold and 4.614-fold respectively (HR: $1.468,95 \% \mathrm{Cl}: 0.70-3.07, P=0.308$; HR: 4.614, 95\%Cl: $1.98-10.74, P$ $<0.001)$. This shows that differentiation grades play more important role in the progression of EOpNET patients. Furthermore, in accordance with the results in SEER cohort, surgery reduced the risks of death significantly in both EOpNET group (HR: $0.080,95 \% \mathrm{Cl}: 0.03-0.20, P<0.001)$ and TOpNET group (HR: 0.168 , 95\%Cl: 0.09-0.31, $P<0.001)$. 


\begin{tabular}{|c|c|c|c|c|c|c|c|c|}
\hline & \multicolumn{4}{|c|}{ Distributions by age at diagnosis } & \multicolumn{4}{|c|}{ Survival associations by age at diagnosis } \\
\hline & \multirow{3}{*}{$\begin{array}{l}\text { N with data } \\
\text { available }\end{array}$} & \multirow{3}{*}{$\begin{array}{l}\text { EOpNET } \\
\text { (age <50) } \\
\mathrm{N}(\%)\end{array}$} & \multirow{3}{*}{$\begin{array}{l}\text { TOpNET } \\
(\text { age } \geq 50) \\
N(\%)\end{array}$} & \multirow{3}{*}{$\begin{array}{l}P \\
\text { values }\end{array}$} & \multirow{2}{*}{\multicolumn{2}{|c|}{$\begin{array}{l}\text { EOpNET }(\text { age }<50) \\
(\mathrm{N}=126 \text {, deaths }= \\
20)\end{array}$}} & \multirow{2}{*}{\multicolumn{2}{|c|}{$\begin{array}{l}\text { TOpNET (age } \geq 50) \\
(\mathrm{N}=204 \text {, deaths }=42)\end{array}$}} \\
\hline & & & & & & & & \\
\hline & & & & & \multicolumn{2}{|c|}{$\begin{array}{l}\mathrm{HR}(95 \% \mathrm{Cl}) \\
P \text { Values }\end{array}$} & $\mathrm{HR}(95 \% \mathrm{Cl})$ & $\begin{array}{l}P \\
\text { Values }\end{array}$ \\
\hline Sex & 330 & & & 0.362 & & & & \\
\hline Male & & $50 \rrbracket 39.7 \% \rrbracket$ & $92 \varangle 45.1 \% \rrbracket$ & & Reference & & Reference & \\
\hline Female & & $76 \rrbracket 60.63 \% \rrbracket$ & $112 \bigotimes 54.9 \% \rrbracket$ & & $0.826 \llbracket 0.34-2.00 \rrbracket$ & 0.67 & $\begin{array}{l}0.759 \otimes 0.41- \\
1.39 \rrbracket\end{array}$ & 0.373 \\
\hline AJCC, 8th & 329 & & & 0.875 & & & & \\
\hline 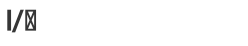 & & $74 \llbracket 58.7 \% \rrbracket$ & $121 \rrbracket 59.6 \% \bigotimes$ & & Reference & & Reference & \\
\hline $\mathbb{\square} / \mathbb{\square}$ & & $52 \llbracket 41.3 \% \rrbracket$ & $82 \varangle 40.4 \% \rrbracket$ & & $\begin{array}{l}19.773 \rrbracket 4.52- \\
86.48 \rrbracket\end{array}$ & 0.000 & $\begin{array}{l}6.715 \rrbracket 3.28- \\
13.77 \rrbracket\end{array}$ & 0.000 \\
\hline AJCC T, 8th & 328 & & & 0.716 & & & & \\
\hline T1 & & $33 \llbracket 26.2 \% \rrbracket$ & $45 \rrbracket 22.3 \% \rrbracket$ & & Reference & & Reference & \\
\hline T2 & & $38 \llbracket 30.2 \% \rrbracket$ & $63 \rrbracket 31.2 \% \rrbracket$ & & $1.241 \rrbracket 0.30-5.20 \rrbracket$ & 0.768 & $\begin{array}{l}\text { 1.194凶0.42- } \\
3.36 \rrbracket\end{array}$ & 0.737 \\
\hline T3 & & $55 \llbracket 43.7 \% \rrbracket$ & $94 \llbracket 46.5 \% \rrbracket$ & & $\begin{array}{l}1.656 \rrbracket 0.464- \\
5.907 \rrbracket\end{array}$ & 0.437 & $\begin{array}{l}2.950 \otimes 0.85- \\
4.98 \rrbracket\end{array}$ & 0.112 \\
\hline AJCC N, 8th & 230 & & & 0.734 & & & & \\
\hline NO & & $75 \rrbracket 83.3 \% \rrbracket$ & 119ه85.0\%凶 & & Reference & & Reference & \\
\hline N1 & & $15 \rrbracket 16.7 \% \rrbracket$ & $21 \rrbracket 15.0 \% \rrbracket$ & & $\begin{array}{l}3.511 \otimes 0.301- \\
41.02 \rrbracket\end{array}$ & 0.317 & $\begin{array}{l}7.074 \rrbracket 2.30- \\
21.73 \rrbracket\end{array}$ & 0.001 \\
\hline AJCC M, 8th & 330 & & & 0.902 & & & & \\
\hline MO & & $90 \otimes 71.4 \% \rrbracket$ & $147 \rrbracket 72.1 \% \rrbracket$ & & Reference & & Reference & \\
\hline M1 & & $36 \rrbracket 28.6 \% \rrbracket$ & $57 \rrbracket 27.9 \% \rrbracket$ & & $\begin{array}{l}23.270 \rrbracket 6.62- \\
81.83 \rrbracket\end{array}$ & 0.000 & $\begin{array}{l}5.830 \rrbracket 3.11- \\
10.95 \rrbracket\end{array}$ & 0.000 \\
\hline Grade (WHO 2010) & 323 & & & 0.936 & & & & \\
\hline G1 & & $48 \bowtie 39.0 \% \rrbracket$ & $74 \llbracket 37.0 \% \rrbracket$ & & Reference & & Reference & \\
\hline G2 & & $59 \llbracket 48.0 \% \rrbracket$ & $99 \varangle 49.5 \% \rrbracket$ & & $\begin{array}{l}9.437 \rrbracket 1.22- \\
73.16 \rrbracket\end{array}$ & 0.032 & $\begin{array}{l}1.468 \rrbracket 0.70- \\
3.07 \rrbracket\end{array}$ & 0.308 \\
\hline G3 & & $16 \rrbracket 13.0 \% \rrbracket$ & $27 \rrbracket 13.5 \% \rrbracket$ & & $\begin{array}{l}30.44 \llbracket 3.81- \\
243.50 \rrbracket\end{array}$ & 0.001 & $\begin{array}{l}4.614 \rrbracket 1.98- \\
10.74 \rrbracket\end{array}$ & 0.000 \\
\hline Primary site & 330 & & & 0.685 & & & & \\
\hline Head & & $46 \rrbracket 36.5 \% \rrbracket$ & $70 \rrbracket 34.3 \% \rrbracket$ & & Reference & & Reference & \\
\hline Body/ Tail & & $80 \rrbracket 63.5 \% \rrbracket$ & $134 \llbracket 65.7 \% \rrbracket$ & & $1.603 \rrbracket 0.58-4.43 \rrbracket$ & 0.363 & $\begin{array}{l}0.945 \rrbracket 0.50- \\
1.78 \rrbracket\end{array}$ & 0.861 \\
\hline Surgery treatment & 330 & & & 0.977 & & & & \\
\hline No & & $19815.1 \% \rrbracket$ & $31 \otimes 15.2 \% \bigotimes$ & & Reference & & Reference & \\
\hline Yes & & $107 \rrbracket 84.9 \% \rrbracket$ & $173 \llbracket 84.8 \% \rrbracket$ & & $0.080 \rrbracket 0.03-0.20 \rrbracket$ & 0.000 & $\begin{array}{l}0.168 \rrbracket 0.09- \\
0.31 \rrbracket\end{array}$ & 0.000 \\
\hline $\begin{array}{l}\text { Median follow up } \\
\text { time (range), } \\
\text { months }\end{array}$ & & $\begin{array}{l}47.97(3.6- \\
152.83)\end{array}$ & $\begin{array}{l}43.87(4.33- \\
128.67)\end{array}$ & & & & & \\
\hline
\end{tabular}

Table 2

Characteristic distributions and survival associations by age at diagnosis among pancreatic neuroendocrine tumor (pNET) cases in FUSCC

We further analyzed the overall survival associations by age at diagnosis of pNET in the two cohorts and Kaplan Meier method and survival curves were formulated (Figure 1). We found in SEER cohort, the overall survival in EOpNET patients was significantly better than among TOpNET patients (136 (3-143) months versus $85(3-143)$ months, $P<0.001)$ with median follow-up time of $92(3-143)$ months. To exclude the other causes of death of pNET patients, we analyzed according to cause specific deaths, the outcome was similar $23(3-142)$ months versus $16(3-142)$ months, $P<0.001)$, with median follow-up time 
of 18 (3-142) months. In FUSCC cohort, the overall survival in EOpNET patients was also better than TOpNET patients with median follow-up time of 39.585 (3.6-152.8) months $(\mathrm{N}=330)$, but was not statistically significant $(P=0.245)$, maybe due to relatively small sample number.

\section{Discussion}

pNETs are relatively rare tumors, its incidence is approximately 5.25/100,000, and majority have satisfying prognosis[4]. However, their clinical features and prognosis are highly heterogeneous, and among them a small percentage of patients displayed malignant characteristics. For example, the overall 5-year survival in metastatic non-functional pNET was only $30 \%$, which bring forth challenges to clinical practice[10]. Therefore, clarifying the clinical characteristics and survival associations could help greatly for the management of pNETs.

In our study, the proportion of EOpNET in FUSCC cohort (38.2\%) was significantly higher than SEER cohort (28.9\%). The average age at diagnosis of pNET in our cohort was $52.6 \pm 12.6$ years, which is earlier compared to SEER database (62 \pm 15$)$ years[4]. The mean age of diagnosis of PDAC in US is reported as 71years, meanwhile in China is 62-65[11, 12]. Hence, it is reasonable to consider differences among different subgroups of races and the similar condition in PDAC. The overall survival of EOpNET (136 (3-143) months) was significantly better than TOpNET (85 (3-143) months) $(P<0.001)$ in SEER database, and also in the FUSCC cohort with median follow-up time of $39.585(3.6-152.8)$ months $(\mathrm{N}=330)$, though not statistically significant $(P=0.245)$, which was consistent with previous reports[9]. In this study, we analyzed both cohorts at 50 years age to keep their consistency, however this could be the reason that certain characteristics in FUSCC cohort are not consistent with or obvious as the SEER database. Therefore, exploring the reasons of different age of onset of disease in different states and races could provide new strategy for therapy in the future.

Surgery is the most effective therapy for localized tumors and even for metastatic NETs that more than $90 \%$ of liver tumors can be resected, cytoreductive surgery is recommended[2]. In our study, we found surgery can lower the risks of death significantly in both EOpNET or TOpNET group. Furthermore, the tumors located in the body and tail had lower risks of death compared to head in TOpNET patients while not in EOpNET patients. This may be associated with worse physical status as the age growth in TOPNET group, as well as patients with tumors located in pancreatic head underwent relatively more invasive surgery of pancreaticoduodenectomy.

Additionally, patients diagnosed between 2010 to 2015 had significantly better prognosis than those diagnosed between 2004 to 2009 , which reflects that with earlier tumor detections due to more prevalent routine medical examinations and the systemic treatment options for pNET have also been adopted considerably in recent years. Somatostatin analogs, peptide receptor radionuclide and everolimus have been demonstrated to effectively improve the prognosis of pNET[13]. Combined chemotherapy with temozolomide and capecitabine is recently reported to prolong the progression-free survival of pNETs[14, 15]. Moreover, our study also shows unmarried patients had significantly higher death risks than the married, which coincides with previous reports suggesting that social support could potentially impact cancer survival significantly [16].

There is no consensus yet on optimal follow-up strategy for pNET. Most guidelines suggest performing enhanced CT or magnetic resonance imaging (MRI) of the abdomen yearly for the first 3 years, then every 1 to 2 years for a total of 10 years[17]. For tumors smaller than $2 \mathrm{~cm}$, previous reports are controversial about observation or operation[18]. While from the perspective of our research, operation is recommended, as EOpNET group had significantly better overall survival than TOPNET.

PNETs are usually sporadic, but increasing evidences suggest the importance of genetic mutations in the initiation and development of pNETs. Jiao et al. performed whole exome sequencing in 68 sporadic pNETs and found that MEN1 (multiple endocrine neoplasia type 1) and DAXX/ATRX (death domainassociated protein/a-thalassemia mental retardation syndrome) mutations are in more than $40 \%$ of pNETs. Also approximately $14 \%$ of specimens had mutations in the genes involved in mTOR pathway which indicated potential therapeutic targets[19]. Scarpa et al. performed whole genome sequencing in 102 primary pNETs and found that germline mutations play more than anticipated important roles to clinically sporadic pNETs[3]. According to the "two-hit" hypothesis[20], gene mutation was closely associated with the onset age of tumor. Therefore, future studies on the variations of genetic mutation among different age groups, especially the early-onset tumor, could help identify pNET driver genes.

The patients were all histology diagnosed in this retrospective study, hence all the patients were either from a surgical database or with positive biopsy results; thus, there may be some bias in the proportion of different stages. However, we queried the SEER database and our institution to minimize the influence of inadequate sample size and geography. Thus, the clinical characteristics of EOpNET and TOpNET and their effects on prognosis were supported and complemented by both cohorts. However, when exploring the survival associations with age at diagnosis, our database is not statistically significant, this may be due to the limited number of samples and the number of deaths. The tumor function was not distinguished, though only a small percent of pNETs were functional; this may cause the bias of prognosis, because functioning neoplasms usually have better prognosis compared to nonfunctioning tumors as a result of early diagnosis.

EOPNET constitute only $28 \%$ to $38 \%$ of the total pNET patients and have better prognosis, however due to young age of onset, the disease is responsible for much more of the total number of years-of-life-lost. Identifying the clinical characteristics and prognosis associations by the onset age of pNET could help us better understand pNET, especially those early onset ones, and potentially yield strategies to delay the onset of it, or help put forward new therapeutic methods.

\section{Conclusions}

EOpNET group had significantly better overall survival than TOpNET though their clinical characteristics seem to be not significantly different, except that the proportion of female and lymph node positive status in EOpNETs was higher than in TOpNET. In the future personalized treatment of pNET, the onset age of patients will become another important factor for guiding the treatment and prognosis. 


\section{Declarations}

\section{Ethics approval and consent to participate}

The study was approved by the ethics committee of Fudan University Shanghai Cancer Center. All patients provided written informed consent.

\section{Consent for publication}

There will be no conflict of commercial interest for any of the patient with the publication of the manuscript.

\section{Availability of data and material}

The datasets used and/or analyzed during the current study are available from the corresponding author on reasonable request.

\section{Competing interests}

The authors declare that they have no competing interests.

\section{Funding}

National Science Fund for Distinguished Young Scholars [grant number 81625016]; Scientific Innovation Project of Shanghai Education Committee (2019-0107-00-07-E00057); National Natural Science Foundation [grant numbers 81502031, 81372651 and 81972725]; Shanghai Health Commission (2018YQ06); Shanghai Municipal Science and Technology Commission (19QA1402100).

\section{Authors' contributions}

M Liu, X. Sun and Z. Zhang contributed equally to this article, collected and analyzed the data, and drafted the manuscript. X. Xu and X. Yu reviewed and contributed to the revision of the manuscript. S. Ji and Q. Zhuo designed and reviewed the study. All authors read and approved the final manuscript.

\section{Acknowledgments}

We thank Professor Min Li for review our manuscript for clarity.

\section{References}

1. Bosman FT, World Health Organization., International Agency for Research on Cancer.: WHO classification of tumours of the digestive system. 4th edn. Lyon: International Agency for Research on Cancer; 2010.

2. Cives M, Strosberg JR: Gastroenteropancreatic Neuroendocrine Tumors. CA Cancer J Clin 2018, 68:471-487.

3. Scarpa A, Chang DK, Nones K, Corbo V, Patch AM, Bailey P, Lawlor RT, Johns AL, Miller DK, Mafficini A, et al: Whole-genome landscape of pancreatic neuroendocrine tumours. Nature 2017, 543:65-71.

4. Yao JC, Hassan M, Phan A, Dagohoy C, Leary C, Mares JE, Abdalla EK, Fleming JB, Vauthey JN, Rashid A, Evans DB: One hundred years after "carcinoid": epidemiology of and prognostic factors for neuroendocrine tumors in 35,825 cases in the United States. J Clin Onco/ 2008, 26:3063-3072.

5. Ben-Aharon I, Elkabets M, Pelossof R, Yu KH, lacubuzio-Donahue CA, Leach SD, Lowery MA, Goodman KA, O'Reilly EM: Genomic Landscape of Pancreatic Adenocarcinoma in Younger versus Older Patients: Does Age Matter? Clin Cancer Res 2019, 25:2185-2193.

6. McWilliams RR, Maisonneuve P, Bamlet WR, Petersen GM, Li D, Risch HA, Yu H, Fontham ET, Luckett B, Bosetti C, et al: Risk Factors for Early-Onset and Very-Early-Onset Pancreatic Adenocarcinoma: A Pancreatic Cancer Case-Control Consortium (PanC4) Analysis. Pancreas 2016, 45:311-316.

7. Beeghly-Fadiel A, Luu HN, Du L, Shi C, McGavic DP, Parikh AA, Raskin L: Early onset pancreatic malignancies: Clinical characteristics and survival associations. Int J Cancer 2016, 139:2169-2177.

8. Luo G, Javed A, Strosberg JR, Jin K, Zhang Y, Liu C, Xu J, Soares K, Weiss MJ, Zheng L, et al: Modified Staging Classification for Pancreatic Neuroendocrine Tumors on the Basis of the American Joint Committee on Cancer and European Neuroendocrine Tumor Society Systems. $J$ Clin Oncol 2017, 35:274-280.

9. Wang Z, Jiang W, Zheng L, Yan J, Dai J, Huang C, Zhang Q, Yin Z, Gong X, Zhang Y: Consideration of Age Is Necessary for Increasing the Accuracy of the AJCC TNM Staging System of Pancreatic Neuroendocrine Tumors. Front Oncol 2019, 9:906.

10. Jilesen AP, van Eijck CH, in't Hof KH, van Dieren S, Gouma DJ, van Dijkum EJ: Postoperative Complications, In-Hospital Mortality and 5-Year Survival After Surgical Resection for Patients with a Pancreatic Neuroendocrine Tumor. A Systematic Review. World J Surg 2016, 40:729-748.

11. Jia X, Du P, Wu K, Xu Z, Fang J, Xu X, Lin K: Pancreatic Cancer Mortality in China: Characteristics and Prediction. Pancreas 2018, 47:233-237.

12. Chen W, Zheng R, Baade PD, Zhang S, Zeng H, Bray F, Jemal A, Yu XQ, He J: Cancer statistics in China, 2015. CA Cancer J Clin 2016, 66:115-132. 
13. Caplin ME, Pavel M, Cwikla JB, Phan AT, Raderer M, Sedlackova E, Cadiot G, Wolin EM, Capdevila J, Wall L, et al: Lanreotide in metastatic enteropancreatic neuroendocrine tumors. N Engl J Med 2014, 371:224-233.

14. de Mestier L, Walter T, Evrard C, de Boissieu P, Hentic O, Cros J, Tougeron D, Lombard-Bohas C, Rebours V, Hammel P, Ruszniewski P: Temozolomide alone or combined to capecitabine for the treatment of advanced pancreatic NET. Neuroendocrinology 2019.

15. Strosberg JR, Fine RL, Choi J, Nasir A, Coppola D, Chen DT, Helm J, Kvols L: First-line chemotherapy with capecitabine and temozolomide in patients with metastatic pancreatic endocrine carcinomas. Cancer 2011, 117:268-275.

16. Aizer AA, Chen MH, McCarthy EP, Mendu ML, Koo S, Wilhite TJ, Graham PL, Choueiri TK, Hoffman KE, Martin NE, et al: Marital status and survival in patients with cancer. J Clin Oncol 2013, 31:3869-3876.

17. Singh S, Moody L, Chan DL, Metz DC, Strosberg J, Asmis T, Bailey DL, Bergsland E, Brendtro K, Carroll R, et al: Follow-up Recommendations for Completely Resected Gastroenteropancreatic Neuroendocrine Tumors. JAMA Oncol 2018, 4:1597-1604.

18. Howe JR, Merchant NB, Conrad C, Keutgen XM, Hallet J, Drebin JA, Minter RM, Lairmore TC, Tseng JF, Zeh HJ, et al: The North American Neuroendocrine Tumor Society Consensus Paper on the Surgical Management of Pancreatic Neuroendocrine Tumors. Pancreas 2020, 49:1-33.

19. Jiao Y, Shi C, Edil BH, de Wilde RF, Klimstra DS, Maitra A, Schulick RD, Tang LH, Wolfgang CL, Choti MA, et al: DAXX/ATRX, MEN1, and mTOR pathway genes are frequently altered in pancreatic neuroendocrine tumors. Science 2011, 331:1199-1203.

20. Knudson AG, Jr.: Mutation and cancer. statistical study of retinoblastoma. Proc Natl Acad Sci U S A 1971, 68:820-823.

\section{Figures}

A
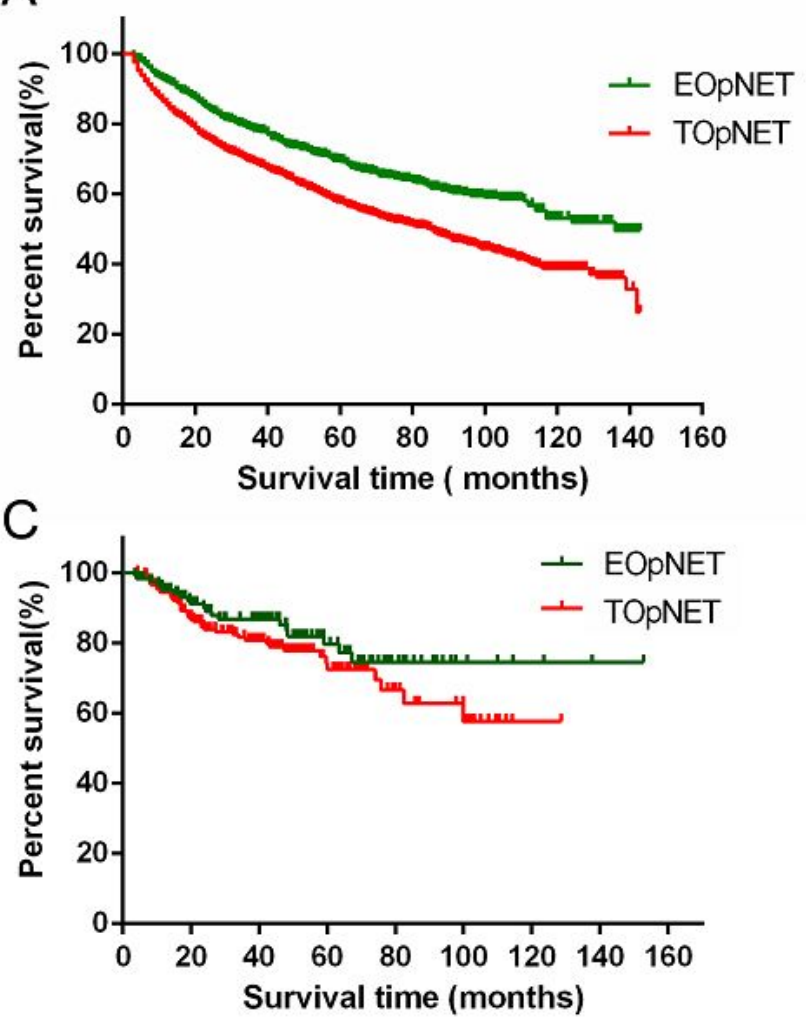

B

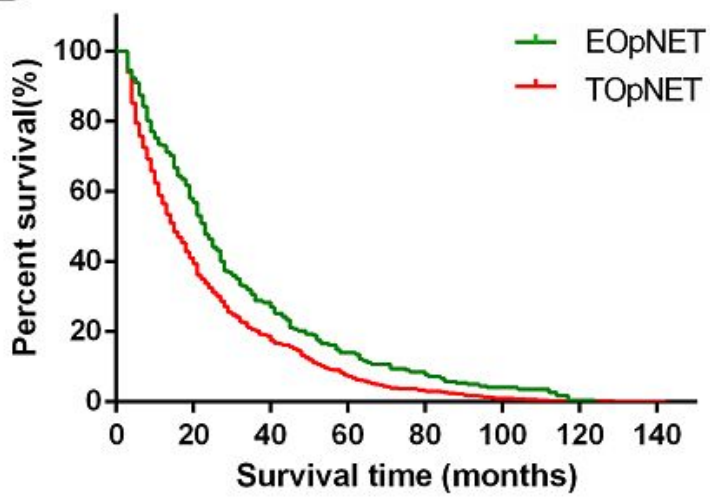

Figure 1

Kaplan-Meier survival curves of EOpNET and TOpNET patients in SEER database (A) all patients (B) cause specific deaths and (C) FUSCC. 